OPEN ACCESS

Edited by:

Heather K. Caldwell, Kent State University, United States

Reviewed by:

Karen Lisa Bales,

University of California, Davis, United States Brian Trainor,

University of California, Davis, United States

Catherine Marler

University of Wisconsin-Madison, United States

*Correspondence: Jack H. Taylor

jhtaylor@unomaha.edu

Specialty section: This article was submitted to Neuroendocrine Science, a section of the journal Frontiers in Endocrinology

Received: 06 June 2017 Accepted: 10 July 2017

Published: 27 July 2017

Citation:

Taylor JH, Intorre AA and French JA (2017) Vasopressin and Oxytocin

Reduce Food Sharing Behavior in Male, but Not Female Marmosets in Family Groups. Front. Endocrinol. 8:181. doi: 10.3389/fendo.2017.00181

\section{Vasopressin and Oxytocin Reduce Food Sharing Behavior in Male, but Not Female Marmosets in Family Groups}

\author{
Jack H. Taylor ${ }^{1,2 *}$, Allison A. Intorre ${ }^{1,2}$ and Jeffrey A. French ${ }^{1,2,3}$ \\ ${ }^{1}$ Department of Psychology, University of Nebraska at Omaha, Omaha, NE, United States, ${ }^{2}$ Callitrichid Research Center, \\ Omaha, NE, United States, ${ }^{3}$ Department of Biology, University of Nebraska at Omaha, Omaha, NE, United States
}

Oxytocin (OT) is critical for lactation and maternal care, but OT and the related nonapeptide vasopressin are important for caregiving behaviors in fathers and alloparents as well. This experiment tested the effects of vasopressin and OT on food sharing in marmoset families. We treated caregivers (parents, siblings) with intranasal vasopressin, OT, or saline, and then paired them with the youngest marmoset in the family. Caregivers were given preferred food, and then observed for food sharing and aggressive behavior with young marmosets. OT reduced food sharing from male alloparents to youngest siblings, and fathers that received vasopressin refused to share food with their youngest offspring more often than when treated with OT. Vasopressin increased aggressive vocalizations directed toward potential food recipients in all classes of caregivers. These results indicate that vasopressin and OT do not always enhance prosocial behavior: modulation of food sharing depends on both sex and parental status.

Keywords: food sharing, provisioning, oxytocin, vasopressin, marmoset, sibling, parental care

\section{INTRODUCTION}

In mammals, mothers begin providing nutritional support (i.e., lactation) immediately after the delivery of offspring, and this process is regulated by the nonapeptide hormone oxytocin $(\mathrm{OT})$ and its cognate receptor (1). OT is also an important modulator of other maternal behaviors in addition to lactation, as demonstrated in multiple experimental approaches. OT administered intracerebroventricularly (i.c.v.) induces maternal behavior in estrogen-primed rats (2), and OT receptor (OTR) antagonists administered directly into the ventral tegmental area, or administered directly into the medial preoptic area block the normal expression of postpartum maternal behavior in rats $(3,4)$, indicating a causal role for OT in the onset of maternal behavior. Arginine vasopressin (AVP), a nonapeptide that is closely related to OT, also modulates maternal behavior. AVP and OT are highly similar nonapeptides, differing at only two amino acid positions, and each can bind and activate the others' receptors [reviewed in Ref. $(5,6)$ ], but often AVP and OT affect different behavioral patterns associated with mother-offspring interactions. Pharmacological manipulations of AVP in the brain indicate that AVP is an important neuromodulator of "active" maternal behavior, including the enhancement of defensive aggression $[(3,4)$; c.f. $(7,8)]$. Data from correlational studies investigating OT or AVP support a role for both nonapeptides in the regulation of maternal care (9-11), though there is some concern over whether peripheral measures of nonapeptides accurately reflect levels 
in the central nervous system $(12,13)$. These experimental and correlational data show that OT and AVP are important neuromodulators of maternal behavior.

There is strong evidence that OT modulates behavior in caregivers other than the mother, including fathers (paternal care), as well as older siblings and unrelated, reproductively inexperienced males and females (alloparental care). OT-like compounds facilitate male parental care in several non-mammalian species $[(14,15)$; c.f. (16)]. OT induces maternal-like behavior in female sheep exposed to unrelated offspring and enhances pup care in reproductively naïve female rats, animals which would not otherwise provide care spontaneously $(2,17,18)$. Moreover, OTR knockdown reduces spontaneous alloparental behavior in female prairie voles (19). Male caregiving behavior is affected by OT as well; i.c.v. OT enhances food provisioning behavior in marmoset monkey fathers (20), and intranasal OT increases responsiveness to infant stimuli in marmoset males (21). In humans, intranasal OT in fathers enhances infant touching and joint father-infant social gaze (22). Correlational data support these pharmacological studies in fathers and alloparents. In general, OT-system activity, measured both peripherally and centrally, increases with caregiving behavior in human fathers (9, 11, 23), non-human alloparents $(24,25)$, and fathers of biparental non-human species (24,26-29). Taken together, these data show that OT is important for modulating the behavior of all caregivers.

Arginine vasopressin and its non-mammalian analogs also affect caregiving behavior in fathers and alloparents. In reproductively inexperienced male prairie voles, i.c.v.-administered AVP enhanced, and a V1aR antagonist inhibited, alloparental behavior (30). Similarly, AVP enhanced responsiveness to infant stimuli in female marmosets [including infant-naïve females (21)]. Correlational data also suggest that AVP-system activity enhances parental behavior. Exposure to young enhances AVPsystem activity in the brain $(27,31-34)$, and enhanced paternal behavior is positively associated with AVP-system activity $(9,35)$. In other species and contexts though, AVP activity inhibits caregiving behavior by non-mothers. AVP administration reduced nest building in biparental old-field mouse fathers, and inhibition of AVP neuron activity enhances nest building in male and female laboratory mice (36). Similarly, V1aR mRNA is downregulated in biparental California mouse fathers, and increased V1aR mRNA expression in California mice is associated with longer latencies to approach pups (28). AVP-mediated inhibition of paternal behavior is present in non-mammals as well; intraperitoneal vasotocin inhibited paternal behavior in poison frogs and clownfish $(14,16)$. In other contexts, the relationship between AVP and caregiving behavior by non-mothers is less clear. AVP administration did not affect responsiveness to infant stimuli in male marmosets (21), and V1aR antagonist treatment in reproductively inexperienced male prairie voles was only effective at reducing alloparental behavior when it was coadministered with an OTR antagonist (37). Thus, the relationship between AVP and caregiving in non-mothers is less clear than the relationship between OT and caregiving in non-mothers, and it is less clear than the relationship between AVP and caregiving behavior in mothers.
Females are the primary provisioners early in mammalian development ( $v i a$ lactation) but in marmosets, mothers, fathers, and alloparents participate in food sharing behavior to infants both during and after weaning. Moreover, the relationship between increased urinary OT and food provisioning in marmosets strengthens during and after weaning (24). To date, only one study has shown that OT manipulation enhances food sharing behavior. Saito and Nakamura (20) treated marmoset fathers with i.c.v. OT and found that OT reduced food sharing refusals to young, a measure of enhanced food provisioning, but not older offspring. OT did not affect active food sharing in fathers, though. We sought to expand Saito and Nakamura's findings by investigating both OT- and AVP-mediated food sharing in all family members. In this experiment, we investigated the influence of AVP and OT on food sharing with juvenile family members by fathers, mothers, and older siblings (alloparents) in marmosets. We treated marmoset mothers, fathers, and alloparents with intransal AVP, OT, or saline control, and then tested their provisioning of rewards in a food sharing paradigm. In this paradigm, caregivers could choose to share or withhold preferred food items with the youngest member of the family. If AVP and OT affect food provisioning via general prosocial mechanisms, then we would expect both AVP and OT to increase food provisioning in all caregivers, regardless of sex or parental status (breeder vs. alloparent). Alternatively, if AVP and OT act via mechanisms specific to sex or parental status of food provisioners, then we would expect differential rates of food provisioning between AVP- and OT-treated mothers, fathers, and alloparents. Because AVP enhanced responsiveness to infant stimuli in marmoset females and OT enhanced responsiveness to infant stimuli in marmoset males (21), we expected a similar pattern with respect to food provisioning; we expected AVP to enhance food sharing behavior in mothers and female alloparents and OT to enhance food sharing behavior in fathers and male alloparents.

\section{MATERIALS AND METHODS}

\section{Subjects}

We used 17 marmosets (Callithrix jacchus) from three different family groups at the University of Nebraska at Omaha's Callitrichid Research Center as subjects. Twelve served as potential food provisioners (four adult parents and eight older sibling alloparents, ages 1.15-6.7 years) and five were juvenile marmosets (30-60 weeks of age) that served as potential food recipients. Breeding females were contracepted with cloprostenol (38) to prevent the confounding effects of the presence of nursing and dependent infants within family groups. Thus, all potential food recipients were the youngest animals in their family groups. Table 1 provides demographic and social information on the animals included in the experiment. Marmosets were housed in large family enclosures $(1.0 \mathrm{~m} \times 2.5 \mathrm{~m} \times 2 \mathrm{~m})$, and each enclosure had two smaller holding areas $(30 \mathrm{~cm} \times 30 \mathrm{~cm} \times 66 \mathrm{~cm}$ each $)$ in which all food sharing trials occurred. Marmosets were fed a daily diet of commercial marmoset diet (Science Diet), at approximately $0900 \mathrm{~h}$, and fresh fruits, eggs, mealworms, and yogurt, at approximately $1500 \mathrm{~h}$. Further details on colony management 
TABLE 1 | Marmoset family demographics and recipient pairings.

\begin{tabular}{|c|c|c|c|}
\hline Family ID & Parents (ages) & $\begin{array}{l}\text { Alloparent siblings } \\
\text { (ages) }\end{array}$ & $\begin{array}{l}\text { Recipient juveniles } \\
\text { (sex/age) }\end{array}$ \\
\hline C1 & $\begin{array}{l}\text { Mother ( } 5.7 \text { years) } \\
\text { Father ( } 6.0 \text { years) }\end{array}$ & & $\begin{array}{l}\text { Juvenile } 1 \text { (F/0.7 years) } \\
\text { Juvenile } 1\end{array}$ \\
\hline C2 & $\begin{array}{l}\text { Mother ( } 6.7 \text { years) } \\
\text { Father ( } 6.7 \text { years) }\end{array}$ & $\begin{array}{l}\text { Male } 1 \text { ( } 2.1 \text { years) } \\
\text { Female } 1 \text { ( } 2.1 \text { years) } \\
\text { Female } 2 \text { ( } 1.2 \text { years) } \\
\text { Male } 2 \text { (1.2 years) }\end{array}$ & $\begin{array}{l}\text { Juvenile } 1 \text { (F/0.7 years) } \\
\text { Juvenile } 2 \text { (F/0.7 years) } \\
\text { Juvenile } 1 \\
\text { Juvenile } 2\end{array}$ \\
\hline C3 & $\begin{array}{l}\text { Mothera ( } 5.7 \text { years) } \\
\text { Father }^{\mathrm{a}}(3.4 \text { years })\end{array}$ & $\begin{array}{l}\text { Female } 1 \text { ( } 2.0 \text { years) } \\
\text { Female } 2 \text { ( } 2.0 \text { years) } \\
\text { Male } 1 \text { ( } 1.6 \text { years) } \\
\text { Male } 2 \text { (1.6 years) }\end{array}$ & $\begin{array}{l}\text { Juvenile } 1(\mathrm{M} / 1.1 \text { years) } \\
\text { Juvenile } 2(\mathrm{M} / 1.1 \text { years) } \\
\text { Juvenile } 1 \\
\text { Juvenile } 2\end{array}$ \\
\hline
\end{tabular}

alndicates these animals were removed from the study because they refused experimenter-provided food.

and husbandry can be found in Ref. (39). All procedures were approved by the University of Nebraska at Omaha/University of Nebraska Medical Center IACUC (\#15-005-04-FC).

\section{Identification of Preferred Food Items}

We wanted to identify foods that were preferred enough by marmosets to elicit consistent food begging by juveniles, but not so highly preferred that provisioners would refuse to share them. We surveyed our colony (four males, six females from Table 1, plus an additional male and an additional female) to identify preferred food items using a two-choice food preference test (40). The food items tested were Science marmoset diet, breakfast cereal (Honey Nut Cheerios( ), apple, and marshmallows. Adult and subadult marmosets were presented with two food items on a tray, separated by $2.5 \mathrm{~cm}$, and we recorded which food item was selected first among each food pair. All possible combinations of food item pairs were presented to each marmoset at least four times, with order of testing food pairs randomized and position of food items on the tray alternated between trials.

\section{Food Sharing Test}

At the beginning of each session, the marmoset serving as food provisioner was briefly manually restrained and treated intranasally with either the variant of OT native to marmosets (Pro ${ }^{8}$-OT; approximately $150 \mu \mathrm{g} / \mathrm{kg}$ ), vasopressin (approximately $133 \mu \mathrm{g} / \mathrm{kg} ; \sim 80 \mathrm{IU})$, or a saline control. Intranasal treatments were applied dropwise in a volume of $50 \mu \mathrm{L}$ per nostril. These doses have been shown to alter social behavior in marmosets and Titi monkeys $(21,41-43)$. Each provisioner was exposed to all three treatments in a counterbalanced order, with at least $48 \mathrm{~h}$ between treatments. Salivary OT in humans returns to near baseline levels in less than $7 \mathrm{~h}$ after intranasal administration (44). The marmoset was returned to the home cage, and a period of 20 min was given to allow uptake of the treatment $(45,46)$. After $20 \mathrm{~min}$, the provisioner and recipient were moved to a holding area within the home cage, eliminating the potential for other family members to interfere with potential food provisioning. The provisioner and the recipient were briefly separated with a slotted barrier, and the provisioner was offered a piece of food in a dish. As soon as the provisioner obtained the food item, we removed the barrier, and interactions between the caregiver and recipient were recorded by a single observer who was blind to experimental treatment condition for the provisioner.

Specific behaviors of interest were begging, food sharing, food sharing refusals, and vocalizations. Begging (count) was recorded when the recipient marmoset made contact with the provisioner when attempting to take the apple or cereal. Food sharing (count, latency) was recorded when the provisioner transferred or allowed recipient to take part or all of the food provided. Food sharing refusals (count) were recorded when a beg occurred, but sharing did not. Begging cries (count) from the recipient and aggressive "Ehr-Ehr" vocalizations (count) by the provisioner were also recorded for each trial. To account for trial-by-trial differences in recipient behavior, we recorded if the recipient did not see (yes/ no) food before it was eaten, recipient appeared to see food, but had no interest (yes/no), and recipient watched (yes/no) caregiver eat food, but did not attempt to take food.

Each session of testing consisted of 20 1-min trials, and apple and cereal were alternated in successive trials. If the provisioner dropped the piece of food before the barrier between the provisioner and recipient was removed, an additional food item was given to the provisioner. Each provisioner:recipient pair was tested under all three experimental conditions (OT, AVP, saline).

\section{Data Analysis}

We used a trial-by-trial analysis to evaluate effects of treatment, sex, and caregiver parental status within the family (parent vs. alloparent). We used a Linear Mixed Model analysis, and nested food sharing trials within testing sessions, sessions within individual marmosets, and marmosets within families. This strategy allowed us to control for trial-by-trial differences in recipient and provisioner hunger status, motivation, or attention, as well as experiment-wide differences in recipient age and family size. Moreover, we were able to appropriately treat families, individuals, and testing sessions as non-independent entities. Our final model is described in Eq. 1. Significant main effects and interactions were explored using Fisher's post hoc tests, using a Satterthwaite approximation for degrees of freedom.

$$
\begin{aligned}
\text { Behaviour }= & \text { Caregiver Sex } \times \text { Treatment } \times \text { Parental Status } \times \text { Food Type } \\
& + \text { Family Size }+ \text { Recipient Age }+ \text { Session Number } \\
& + \text { Trial Number }+ \text { Recipient Interest }{ }^{\mathrm{a}} \\
& + \text { error }(\text { FamilyID })+\text { error(MonkeyID }) \\
& + \text { error }(\text { SessionID })+\text { error(residual })
\end{aligned}
$$

Equation 1. Template model for analysis of behavioral data. Bolded variables indicate primary tests of hypotheses. ${ }^{a}$ Recipient Interest was composed of three separate variables and corresponding regression coefficients: recipient did not see food before it was eaten, recipient appeared to see food, but had no interest, and recipient watched caregiver eat food, but did not attempt to take food.

\section{RESULTS}

\section{Food Preference}

Adult marmosets showed a clear hierarchical preference profile for the four food items we tested. Standard diet was never preferred 
over other foods, and marshmallows were always preferred over other foods. However, there was no overall preference for apples vs. cereal (Table 2, bolded), thus apples and cereal were intermediate in preference compared to diet and marshmallow. In order to maximize food begging while optimizing rates of food sharing (i.e., prevent floor or ceiling effects due to food preference), we chose apples and cereal as our food items in our food sharing test.

\section{Food Sharing Test}

Food sharing was associated with the parental status of the provisioner, and it was affected by the interaction between parental status and nonapeptide treatment. Mothers shared more often than fathers, but otherwise there were no differences in rates of food sharing among parents or alloparents [Figure 1; $\left.F_{(1,13.65)}=6.23, p=0.026\right]$. Mothers also had shorter latencies to share food than fathers and female alloparents [Figure 2; $F_{(1,13.7)}=7.28, p=0.018$ ]. Male alloparents were the only family members whose rates of food sharing were altered by nonapeptide treatment. In male alloparents, Pro $^{8}$-OT reduced food sharing compared to AVP and saline $\left[F_{(2,26.3)}=3.45, p=0.047\right]$, but neither Pro ${ }^{8}$-OT nor AVP changed rates of food sharing in

TABLE 2 | Choice matrix for all food items paired with all other food items.

\begin{tabular}{lcccc}
\hline & \multicolumn{4}{c}{ Chosen food (\%) } \\
\cline { 2 - 5 } Paired food & Diet & Apple & Cereal & Marshmallow \\
\hline Diet & - & $100^{\mathrm{a}}$ & $97.9^{\mathrm{a}}$ & $100^{\mathrm{a}}$ \\
Apple & & - & $\mathbf{6 2 . 5}$ & $70.8^{\mathrm{a}}$ \\
Cereal & & & - & $70.8^{\mathrm{a}}$ \\
Marshmallow & & & & -
\end{tabular}

Bold values indicate no significant preference for chosen food over paired food. a/ndicate percentage for chosen food was significantly different from $50 \%$ [t(11) $>2.41$, $p<0.05]$.

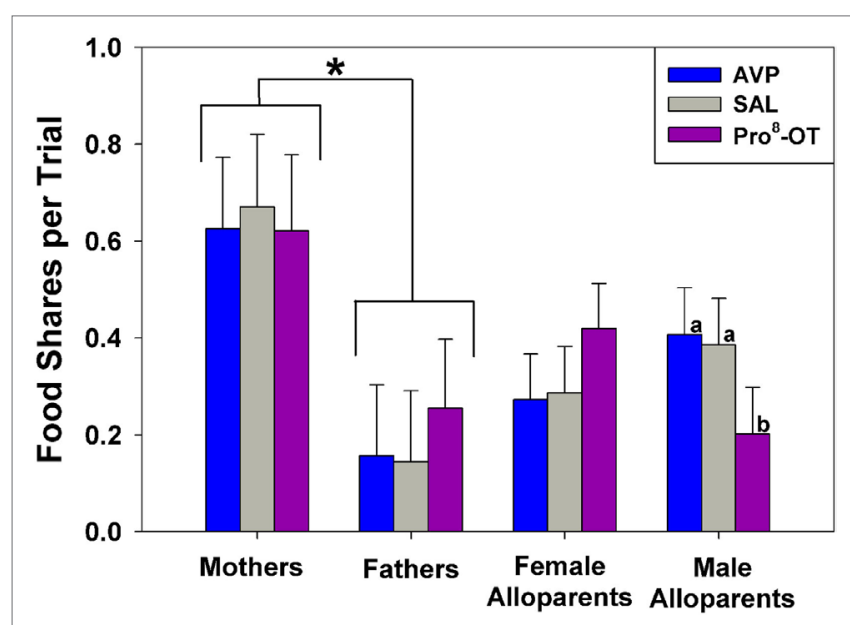

FIGURE 1 | Food sharing from caregivers (parents, alloparents) to the youngest family members. Mothers shared significantly more than fathers did. Male alloparents treated with Pro $^{8}$-oxytocin (OT) shared less than when they were treated with saline or arginine vasopressin (AVP). Asterisks indicate significant differences between social roles using a Fisher's post hoc test $(p<0.05)$. Bars with differing letters indicate significant differences across treatments within individuals using a Fisher's post hoc test. mothers, fathers, or female alloparents nor did it affect latencies to share. Provisioners shared marginally, but not significantly, more often $\left[F_{(1,11.29)}=3.78, p=0.07\right.$; Table $S 1$ in Supplementary Material] and faster to younger recipients than to older recipients $\left[F_{(1,11.31)}=4.31, p=0.06\right.$, Table S2 in Supplementary Material $]$.

Food sharing refusals were also associated with the parental status of the provisioner with the family, and food sharing was also affected by the interaction between parental status and nonapeptide treatment (Figure 3). Just as mothers shared more often than other caregivers, mothers also refused to share less often than any other caregivers [Figure 3, brackets; $F_{(1,42.4)}=14.38$, $p<0.001]$. Fathers were the only family members whose rates

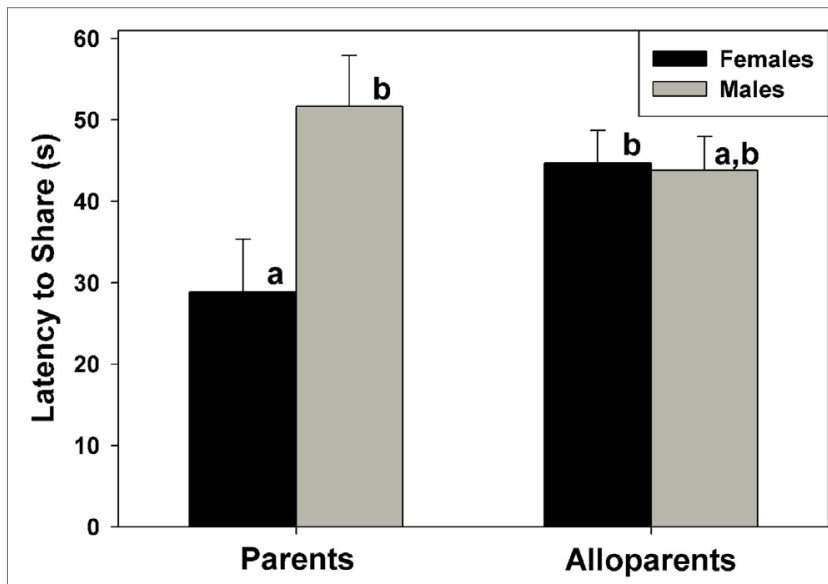

FIGURE 2 | Latency for caregivers (parents, alloparents) to share food to the youngest family members. Mothers shared significantly faster than fathers and female alloparents. Bars with differing letters indicate significant differences between social roles using a Fisher's post hoc test.

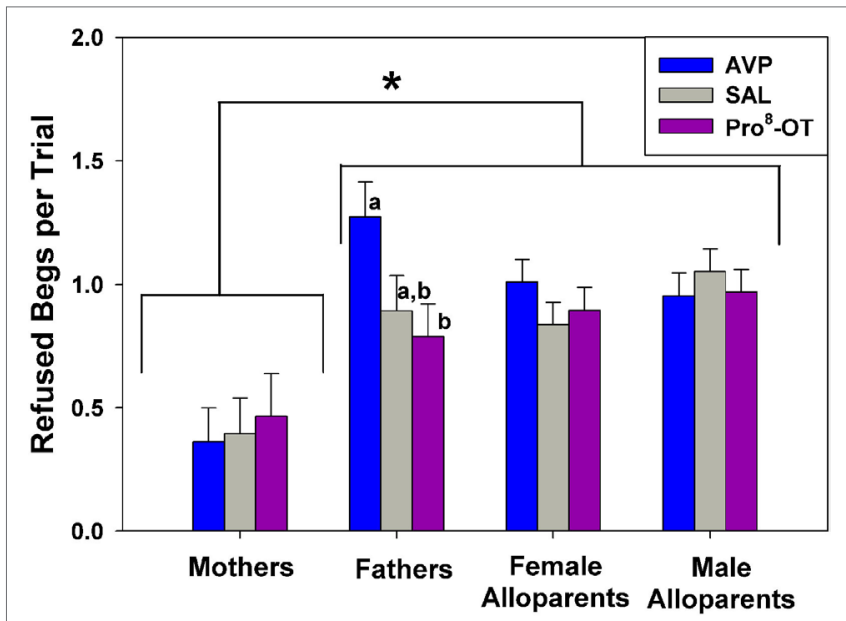

FIGURE 3 | Caregiver (parents, alloparents) food share refusals after a recipient food beg. Mothers refused to share food less often than any other caregiver group. Fathers treated with arginine vasopressin (AVP) refused more when treated with AVP compared to Pro ${ }^{8}$-oxytocin (OT). Asterisks indicate significant differences between social roles using a Fisher's post hoc test $(p<0.05)$. Bars with differing letters indicate significant differences across treatments within individuals using a Fisher's post hoc test. 
of food sharing refusal were affected by nonapeptide treatment. Fathers treated with AVP had higher rates of food sharing refusals than when treated with Pro $^{8}$-OT [Figure 3, letters; $F_{(2,39.9)}=3.24$, $p=0.050]$. Recipient age did not affect food sharing refusals $\left[F_{(1,33.04)}=2.64, p=0.11\right]$.

Aggressive vocalizations (Ehr-Ehr) emitted by the provisioner during the food sharing test were associated with the parental status of the provisioner, as well as nonapeptide treatment. Alloparents emitted more aggressive vocalizations than parents $\operatorname{did}\left[F_{(1,694)}=13.52, p<0.001\right.$; alloparents, $\mathrm{M}( \pm \mathrm{SEM})=0.3$ (0.03) vocalizations per trial; parents, $\mathrm{M}( \pm$ SEM $)=0.069(0.05)$ vocalizations per trial]. Additionally, AVP increased aggressive vocalizations in provisioners compared to both $\mathrm{Pro}^{8}$-OT and saline in both parents and alloparents [Figure 4; $F_{(2,694)}=4.49$, $p=0.012]$. There were no sex differences in provisioner aggressive vocalizations $\left[F_{(1,694)}=0.02, p=0.877\right]$, and sex did not interact with nonapeptide treatment or parental status $\left[F_{\mathrm{S}}<0.31\right.$, $p$ 's $>0.640$ ]. Provisioners emitted marginally, but not significantly, more aggressive vocalizations toward younger recipients than they did toward older recipients $\left[F_{(1,694)}=2.99, p=0.08\right.$, Table S4 in Supplementary Material].

Finally, we evaluated whether nonapeptide treatment of provisioners altered rates of begging cries emitted by recipients. Nonapeptide treatment of the provisioner did not affect recipient begging cries, nor did parental status of the provisioner or the interaction $\left(F_{S}<2.24, p>0.05\right)$. Begging cries did, however, vary by the recipient's age; older recipients exhibited fewer begging cries than younger recipients $\left[b=-0.0034, F_{(1,11.2)}=5.38, p=0.040\right]$.

\section{DISCUSSION}

In marmosets, all family members perform post-weaning caregiving behavior in the form of food sharing, and we showed that nonapeptide treatment altered food sharing behavior in some, but not all, caregivers. Overall, mothers consistently provisioned food to recipients more frequently than fathers or alloparents

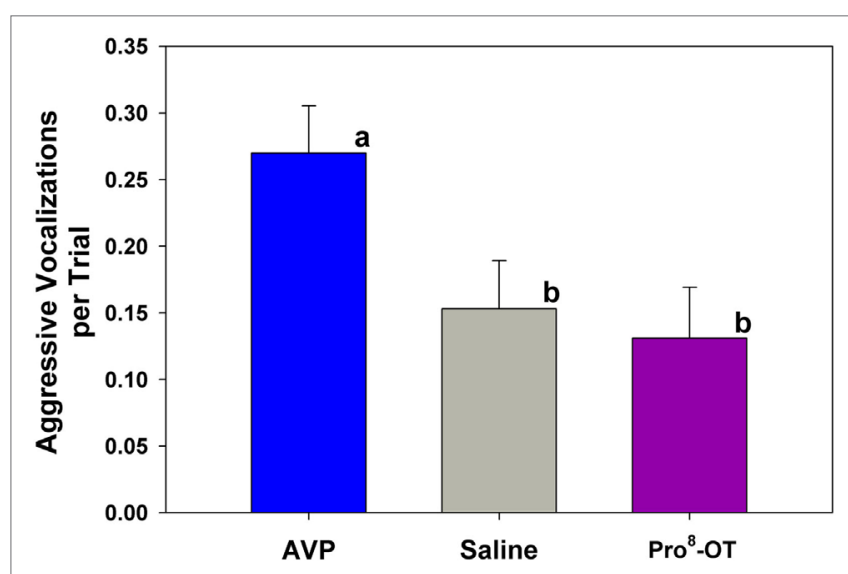

FIGURE 4 | Aggressive vocalization emitted by caregivers (parents, alloparents). Treatment with arginine vasopressin (AVP) increased aggressive vocalizations compared to saline, Pro ${ }^{8}$-oxytocin (OT). Bars with differing letters indicate significant differences across treatments using a Fisher's post hoc test. did, and food provisioning behavior by mothers and female alloparents was not altered by manipulations of AVP or OT. The food provisioning behavior of male alloparents and fathers, however, was altered by AVP and OT treatment. Contrary to our hypothesis, AVP decreased provisioning behavior in fathers, and OT decreased provisioning behavior in male alloparents.

Previous studies in our lab indicated that AVP and OT enhance parental behavior and food sharing in marmosets. Food sharing among adults toward the pair mate was reduced following OTR antagonist treatment, suggesting that OT is important for prosocial food sharing behavior within the family (47). In a simulated infant distress paradigm, AVP enhanced responsiveness to infant stimuli in females, and OT enhanced responsiveness to infant stimuli in males (21), so we had expected to observe the same pattern with regard to food provisioning to juveniles; we expected AVP to enhance caregiving behavior in females, and OT to enhance caregiving behavior in males. However, in the context of maintaining monogamous pair bonds, previous work in our lab has provided evidence that OT may not always enhance prosocial behavior. OT did not enhance behavior directed toward the pair mate, but rather it reduced prosocial food sharing and sociosexual behavior directed toward opposite-sex strangers, thereby enhancing fidelity to the established pair mate $(41,43)$. Thus, AVP and OT may not enhance prosocial behavior generally, instead they may alter social decision-making based on context and social relationships.

We designed this experiment to expand upon the work done by Saito and Nakamura (20), who demonstrated that OT enhances food sharing in fathers toward younger (7-16 weeks), but not older (24-31 weeks) offspring. We expanded on the age range, and showed that OT does not alter paternal food sharing behavior toward older offspring (36-57 weeks). We used a different dose of OT and method of administration that Saito and Nakamura (20), and found no effect of OT on food sharing behavior toward older offspring in fathers. Escalating doses of OT and AVP produce differential behavioral effects in other species [e.g., Ref. $(42,48-50)$ ] and it is likely that the same is true in marmosets. We used a single dose of each nonapeptide that affects adult pair-bonding behavior (41-43), but it may be the case that varying doses may have had differential behavioral effects in this context. With regard to fathers though, OT did not affect food sharing behavior at our intranasal dose or the i.c.v. dose used by Saito and Nakamura (20). An important distinction between our study and Saito and Nakamura's (20) is that the OT ligand used differed: Saito and Nakamura used the conserved mammalian variant of $\mathrm{OT}\left(\mathrm{Leu}^{8}-\mathrm{OT}\right)$, while we used the variant native to marmosets, $\mathrm{Pro}^{8}$-OT. Pro ${ }^{8}$-OT and $\mathrm{Leu}^{8}$-OT differentially affect marmoset social behavior in some contexts of adult pair bonds $(41,43,51,52)$. We also treated marmosets with AVP in our food sharing task, and compared to treatment with $\mathrm{Pro}^{8}$-OT. Like Saito and Nakamura, we found that OT at these doses did not affect paternal food sharing toward older offspring, and that AVP at this dose inhibited paternal food sharing behavior. We also included mothers and alloparents, and found that OT inhibited food sharing behavior in male alloparents. Our findings, combined with those of Saito and Nakamura, demonstrate that behavioral modification via AVP and OT is flexible; AVP- and OT-mediated 
food sharing behavior depends on multiple factors, including offspring age, caregiver sex, and parental status.

Food sharing behavior in primates is the product of multiple demographic and contextual variables. The relationship between OT and caregiving behavior in marmosets change with offspring age $(20,24)$, suggesting that OT modulates caregiving behavior dynamically with changing offspring and caregiver needs. Moreover, in large marmoset families, offspring age, caregiver experience, sex, and parental status interact to produce differential food provisioning behavior. Tolerance for food begging in adult marmosets wanes as offspring mature (53), reflecting reduced responsivity to signals for continued care from older offspring. Food sharing behavior in alloparents is also modulated by multiple variables, including sex and experience. Previous experience in rearing infants is associated with improved food sharing in male, but not female alloparents during undisturbed conditions (54). In an experimental task in which a response provided food to a younger family member, mothers, fathers, and male alloparents all selectively provided food to younger family members, but female alloparents exhibited lower scores on this measure (55). There is some evidence supporting the role of OT in altering social decision-making depending on social context, rather than enhancing global prosociality. In macaques, OT increases the willingness of male macaques to reward another macaque, but only when the alternative is to reward no one. However, when choosing to reward the self or another, OT increased selfish choices (56). In pair-bonded adult marmosets, OT does not increase food sharing with the pair mate, it instead decreases food sharing with an opposite-sex stranger (43). OT also reduces food sharing in group-housed adult capuchin monkeys, and it was suggested that this was mediated by OT-induced increases in social distance (57). It is likely that interactions between older and younger siblings, neither of which are wholly dependent on caregivers, will yield some selfish decision-making that is altered by hormonal neuromodulators like OT and AVP. Our findings speak to the broader issue of whether OT and AVP enhance prosocial behavior generally, or whether they alter social behavior depending on social context. We found that OT and AVP inhibited food sharing behavior, suggesting that OT and AVP alter social behavior depending on characteristics of the caregiver, rather than global enhancement of prosociality.

Arginine vasopressin is known to affect a wide range of aggressive behaviors, including maternal aggression $[(3,4,10)$; c.f. $(7,8)]$, as well as territorial aggression [reviewed in Ref. (58)]. In general, the association between AVP and defense of offspring is limited to females (reviewed in Section "Introduction"), though not always (31), while AVP-mediated modulation of territorial aggression is often limited to males [reviewed in Ref. (58)]. We found that AVP increased aggressive vocalizations during food sharing trials, in males and females, as well as in parents and alloparents. There are two explanations for our lack of a sex effect. First, food aggression, maternal aggression, and territorial aggression may be controlled by different endocrine mechanisms, including AVP and OT. There is some evidence for this, as AVP $\mathrm{V} 1 \mathrm{~b}$ receptor knockout mice display impaired maternal and territorial aggression, but predatory aggression remains intact, suggesting that food aggression is different from defending offspring or territory $(59,60)$. However, while V1b knockout mice do compete for food, they do not compete as aggressively as wild types (59), weakening this argument. An alternative explanation for our lack of a sex effect in AVP-mediated aggression is that AVP and OT may affect aggressive behavior differently in primates than it does in rodents. There is some evidence for this, $\mathrm{V} 1 \mathrm{~b}$ receptor genetic polymorphisms human children are associated with aggression in both boys and girls, though they are more robust in boys than in girls $(61,62)$. Our findings highlight the need for more continued study of AVP, OT, and aggression in non-human primate models.

Oxytocin and AVP are involved in the modulation of dyadic interactions that are dependent on the behavior of both individuals. In humans, intranasal OT treatment in fathers enhances social reciprocity between father and infant, it also causes an increase in infant salivary OT and duration of social gaze (22). Similarly, high paternal plasma and salivary OT in human mothers and fathers is associated with father-infant coordination of affect $(23,63)$. Both AVP and OT are associated with dyadic interactions involving responding to infant gaze (9). This work in humans suggests that OT and AVP in the caregiver can affect behavior in the recipient. Previous work in our lab has shown that the behavior of an untreated marmoset is altered by OT treatment of the pair mate, suggesting that nonapeptides might alter the social attractiveness of a social partner (52). There is an important dyadic component to our measure of food sharing refusals. AVP-mediated increases in refusals may be the result of stable rates of begging and increased rates of refusal, or it may be the result of both increased rates of begging and increased refusal. However, begging cries emitted by the recipient were unaffected by nonapeptide treatment, suggesting that the behavior of recipients did not change in response to altered stimulus properties or any unobserved behavior of the caregiver.

There is considerable overlap between the OT and AVP systems in terms of neuroanatomical distributions [Reviewed in Ref. (64)] and receptor affinity [Reviewed in Ref. (6)], and there are also often important sex and species differences in the effects of OT and AVP on behavior. Given the considerable variation in NWM species OTRs and V1aRs, interactions between Pro ${ }^{8}-\mathrm{OT}$ and V1aR (or AVP and marmoset OTR) may be either reduced (i.e., greater receptor selectivity) or enhanced (i.e., greater receptor promiscuity) compared to humans, mice, and rats. Currently, the binding affinities and signaling potencies/efficacies of these ligand-receptor complexes is unknown. When AVP and OT are studied together, they provide valuable insights on these closely related systems, such as showing that OT and AVP act via one another's receptors, and that they affect behavior synergistically. For example, both AVP and OT induce territorial marking in Syrian hamsters, but OT-induced marking is blocked by AVP receptor antagonists, not OTR antagonists (65). Similarly, blocking both OTRs and V1aRs reduced alloparental behavior in male voles, but blocking only one of these receptor types did not, indicating that AVP and OT work in concert to modulate male vole parental behavior (37). We found that AVP increased food sharing refusals in fathers, but not in male alloparents. Instead, for male alloparents, OT reduced total food sharing. These examples show that more information and nuance are gained from studying AVP and OT together than the sum of what is gained from studying each individually. These studies highlight 
the importance of comparing OT and AVP, especially in species with complex behavior and interindividual relationships.

\section{ETHICS STATEMENT}

This study was carried out in accordance with the recommendations of the University of Nebraska Medical Center/University of Nebraska at Omaha Institutional Animal Care and Use Committee. The protocol was approved by the University of Nebraska Medical Center/University of Nebraska at Omaha Institutional Animal Care and Use Committee (protocol \#15-005-04-FC).

\section{AUTHOR CONTRIBUTIONS}

JT, AI, and JF planned the experiment. JT and AI carried out the experiment under the supervision of JF. JT performed statistics, and JT, AI, and JF each contributed to writing and editing of the manuscript.

\section{REFERENCES}

1. Lee H-J, Caldwell HK, Macbeth AH, Tolu SG, Young WS. A conditional knockout mouse line of the oxytocin receptor. Endocrinology (2008) 149(7):3256-63. doi:10.1210/en.2007-1710

2. Pedersen CA, Ascher JA, Monroe YL, Prange AJ. Oxytocin induces maternal behavior in virgin female rats. Science (1982) 216(4546):648-50. doi:10.1126/ science.7071605

3. Bosch OJ, Neumann ID. Brain vasopressin is an important regulator of maternal behavior independent of dams' trait anxiety. Proc Natl Acad Sci US A (2008) 105(44):17139-44. doi:10.1073/pnas.0807412105

4. Pedersen CA, Caldwell JD, Walker C, Ayers G, Mason GA. Oxytocin activates the postpartum onset of rat maternal behavior in the ventral tegmental and medial preoptic areas. Behav Neurosci (1994) 108(6):1163. doi:10.1037/0735-7044.108.6.1163

5. Gimpl G, Fahrenholz F. The oxytocin receptor system: structure, function, and regulation. Physiol Rev (2001) 81(2):629-83.

6. Gruber CW, Koehbach J, Muttenthaler M. Exploring bioactive peptides from natural sources for oxytocin and vasopressin drug discovery. Future Med Chem (2012) 4(14):1791-8. doi:10.4155/fmc.12.108

7. Nephew BC, Bridges RS. Central actions of arginine vasopressin and a V1a receptor antagonist on maternal aggression, maternal behavior, and grooming in lactating rats. Pharmacol Biochem Behav (2008) 91(1):77-83. doi:10.1016/j. pbb.2008.06.013

8. Nephew BC, Byrnes EM, Bridges RS. Vasopressin mediates enhanced offspring protection in multiparous rats. Neuropharmacology (2010) 58(1):102-6. doi:10.1016/j.neuropharm.2009.06.032

9. Apter-Levi Y, Zagoory-Sharon O, Feldman R. Oxytocin and vasopressin support distinct configurations of social synchrony. Brain Res (2014) 1580:124-32. doi:10.1016/j.brainres.2013.10.052

10. Bosch OJ, Neumann ID. Vasopressin released within the central amygdala promotes maternal aggression. Eur JNeurosci (2010) 31(5):883-91. doi:10.1111/j.1460-9568.2010.07115.x

11. Feldman R, Gordon I, Schneiderman I, Weisman O, Zagoory-Sharon O. Natural variations in maternal and paternal care are associated with systematic changes in oxytocin following parent-infant contact. Psychoneuroendocrinology (2010) 35(8):1133-41. doi:10.1016/j.psyneuen.2010.01.013

12. McCullough ME, Churchland PS, Mendez AJ. Problems with measuring peripheral oxytocin: can the data on oxytocin and human behavior be trusted? Neurosci Biobehav Rev (2013) 37(8):1485-92. doi:10.1016/j. neubiorev.2013.04.018

13. Valstad M, Alvares GA, Egknud M, Matziorinis AM, Andreassen OA, Westlye LT, et al. The correlation between central and peripheral oxytocin

\section{ACKNOWLEDGMENTS}

The authors would like to thank members of the French lab for providing quality feedback during the preparation of this manuscript, and the authors would like to thank Heather Jensen and Dr. Gunkelman for providing excellent care of our animals. This research was funded by grants from the National Institutes of Health (HD089147, awarded to JF) and the University of Nebraska at Omaha's Fund for Undergraduate Scholarly Experiences (awarded to AI, Title: "The Roles of Oxytocin and Vasopressin in Modulating Caregiver Responses to Juvenile Marmoset Monkeys"). The authors declare no financial conflicts of interest.

\section{SUPPLEMENTARY MATERIAL}

The Supplementary Material for this article can be found online at http://journal.frontiersin.org/article/10.3389/fendo.2017.00181/ full\#supplementary-material.

concentrations: a systematic review and meta-analysis. Neurosci Biobehav $\operatorname{Rev}(2017)$. Available from: http://www.sciencedirect.com/science/article/pii/ S0149763417301446

14. DeAngelis R, Gogola J, Dodd L, Rhodes JS. Opposite effects of nonapeptide antagonists on paternal behavior in the teleost fish Amphiprion ocellaris. Horm Behav (2017) 90:113-9. doi:10.1016/j.yhbeh.2017.02.013

15. O'Connell LA, Matthews BJ, Hofmann HA. Isotocin regulates paternal care in a monogamous cichlid fish. Horm Behav (2012) 61(5):725-33. doi:10.1016/j. yhbeh.2012.03.009

16. Schulte LM, Summers K. Searching for hormonal facilitators: are vasotocin and mesotocin involved in parental care behaviors in poison frogs? Physio Behav (2017) 174:74-82. doi:10.1016/j.physbeh.2017.03.005

17. Kendrick KM, Keverne EB, Baldwin BA. Intracerebroventricular oxytocin stimulates maternal behaviour in the sheep. Neuroendocrinology (1987) 46(1):56-61. doi:10.1159/000124796

18. Pedersen CA, Prange AJ. Induction of maternal behavior in virgin rats after intracerebroventricular administration of oxytocin. Proc Natl Acad Sci U S A (1979) 76(12):6661-5. doi:10.1073/pnas.76.12.6661

19. Keebaugh AC, Young LJ. Increasing oxytocin receptor expression in the nucleus accumbens of pre-pubertal female prairie voles enhances alloparental responsiveness and partner preference formation as adults. Horm Behav (2011) 60(5):498-504. doi:10.1016/j.yhbeh.2011.07.018

20. Saito A, Nakamura K. Oxytocin changes primate paternal tolerance to offspring in food transfer. J Comp Physiol A (2011) 197(4):329-37. doi:10.1007/ s00359-010-0617-2

21. Taylor JH, French JA. Oxytocin and vasopressin enhance responsiveness to infant stimuli in adult marmosets. Horm Behav (2015) 75:154-9. doi:10.1016/j. yhbeh.2015.10.002

22. Weisman O, Zagoory-Sharon O, Feldman R. Oxytocin administration to parent enhances infant physiological and behavioral readiness for social engagement. Biol Psychiatry (2012) 72(12):982-9. doi:10.1016/j.biopsych.2012.06.011

23. Gordon I, Zagoory-Sharon O, Leckman JF, Feldman R. Prolactin, oxytocin, and the development of paternal behavior across the first six months of fatherhood. Horm Behav (2010) 58(3):513-8. doi:10.1016/j.yhbeh.2010.04.007

24. Finkenwirth C, Martins E, Deschner T, Burkart JM. Oxytocin is associated with infant-care behavior and motivation in cooperatively breeding marmoset monkeys. Horm Behav (2016) 80:10-8. doi:10.1016/j.yhbeh.2016.01.008

25. Okabe S, Tsuneoka Y, Takahashi A, Ooyama R, Watarai A, Maeda S, et al. Pup exposure facilitates retrieving behavior via the oxytocin neural system in female mice. Psychoneuroendocrinology (2017) 79:20-30. doi:10.1016/j. psyneuen.2017.01.036

26. Gubernick DJ, Winslow JT, Jensen P, Jeanotte L, Bowen J. Oxytocin changes in males over the reproductive cycle in the monogamous, biparental California 
mouse, Peromyscus californicus. Horm Behav (1995) 29(1):59-73. doi:10.1006/ hbeh.1995.1005

27. Kenkel WM, Paredes J, Yee JR, Pournajafi-Nazarloo H, Bales KL, Carter CS. Neuroendocrine and behavioural responses to exposure to an infant in male prairie voles. J Neuroendocrinol (2012) 24(6):874-86. doi:10.1111/ j.1365-2826.2012.02301.x

28. Perea-Rodriguez JP, Takahashi EY, Amador TM, Hao RC, Saltzman W, Trainor BC. Effects of reproductive experience on central expression of progesterone, oestrogen $\alpha$, oxytocin, and vasopressin receptor mRNA in male California mice (Peromyscus californicus). J Neuroendocrinol (2015) 27(4):245-52. doi:10.1111/jne.12264

29. Woller MJ, Sosa ME, Chiang Y, Prudom SL, Keelty P, Moore JE, et al. Differential hypothalamic secretion of neurocrines in male common marmosets: parental experience effects? J Neuroendocrinol (2012) 24(3):413-21. doi:10.1111/j.1365-2826.2011.02252.x

30. Wang ZX, De Vries G, Ferris CF. The role of septal vasopressin innervation in paternal behavior in prairie voles (Microtus ochrogaster). Proc Natl Acad Sci U S A (1994) 91:400-4. doi:10.1073/pnas.91.1.400

31. Kleszczyńska A, Sokołowska E, Kulczykowska E. Variation in brain arginine vasotocin (AVT) and isotocin (IT) levels with reproductive stage and social status in males of three-spined stickleback (Gasterosteus aculeatus). Gen Comp Endocrinol (2012) 175(2):290-6. doi:10.1016/j.ygcen.2011.11.022

32. Kozorovitskiy Y, Hughes M, Lee K, Gould E. Fatherhood affects dendritic spines and vasopressin V1a receptors in the primate prefrontal cortex. Nat Neurosci (2006) 9(9):1094-5. doi:10.1038/nn1753

33. Ripley JL, Foran CM. Quantification of whole brain arginine vasotocin for two Syngnathus pipefishes: elevated concentrations correlated with paternal brooding. Fish Physiol Biochem (2010) 36(4):867-74. doi:10.1007/ s10695-009-9361-3

34. Wang ZX, Liu Y, Young LJ, Insel TR. Hypothalamic vasopressin gene expression increases in both males and females postpartum in a biparental rodent. J Neuroendocrinol (2000) 12(2):111-20. doi:10.1046/ j.1365-2826.2000.00435.x

35. Bester-Meredith JK, Marler CA. Vasopressin and the transmission of paternal behavior across generations in mated, cross-fostered Peromyscus mice. Behav Neurosci (2003) 117(3):455-63. doi:10.1037/0735-7044.117.3.455

36. Bendesky A, Kwon Y-M, Lassance J-M, Lewarch CL, Yao S, Peterson BK, et al. The genetic basis of parental care evolution in monogamous mice. Nature (2017) 544(7651):434-9. doi:10.1038/nature22074

37. Bales KL, Kim AJ, Lewis-Reese AD, Carter CS. Both oxytocin and vasopressin may influence alloparental behavior in male prairie voles. Horm Behav (2004) 45(5):354-61. doi:10.1016/j.yhbeh.2004.01.004

38. Mustoe AC, Jensen HA, French JA. Describing ovarian cycles, pregnancy characteristics, and the use of contraception in female white-faced marmosets, Callithrix geoffroyi. Am J Primatol (2012) 74(11):1044-53. doi:10.1002/ ajp. 22058

39. Schaffner CM, Shepherd RE, Santos CV, French JA. Development of heterosexual relationships in Wied's black tufted-ear marmosets (Callithrix kuhli). Am J Primatol (1995) 36(3):185-200. doi:10.1002/ajp.1350360303

40. Benz JJ, Leger DW, French JA. Relation between food preference and food-elicited vocalizations in golden lion tamarins (Leontopithecus rosalia). J Comp Psychol (1992) 106(2):142-9. doi:10.1037/0735-7036.106.2.142

41. Cavanaugh J, Mustoe AC, Taylor JH, French JA. Oxytocin facilitates fidelity in well-established marmoset pairs by reducing sociosexual behavior toward opposite-sex strangers. Psychoneuroendocrinology (2014) 49:1-10. doi:10.1016/j.psyneuen.2014.06.020

42. Jarcho MR, Mendoza SP, Mason WA, Yang X, Bales KL. Intranasal vasopressin affects pair bonding and peripheral gene expression in male Callicebus cupreus. Genes Brain Behav (2011) 10(3):375-83. doi:10.1111/ j.1601-183X.2010.00677.x

43. Mustoe AC, Cavanaugh J, Harnisch AM, Thompson BE, French JA. Do marmosets care to share? Oxytocin treatment reduces prosocial behavior toward strangers. Hormones and Behavior (2015) 71:83-90. doi:10.1016/j. yhbeh.2015.04.015

44. van IJzendoorn MH, Bhandari R, van der Veen R, Grewen KM, BakermansKranenburg MJ. Elevated salivary levels of oxytocin persist more than $7 \mathrm{~h}$ after intranasal administration. Front Neurosci (2012) 6:174. doi:10.3389/ fnins.2012.00174
45. Born J, Lange T, Kern W, McGregor GP, Bickel U, Fehm HL. Sniffing neuropeptides: a transnasal approach to the human brain. Nat Neurosci (2002) 5(6):514-6. doi:10.1038/nn849

46. Neumann ID, Maloumby R, Beiderbeck DI, Lukas M, Landgraf R. Increased brain and plasma oxytocin after nasal and peripheral administration in rats and mice. Psychoneuroendocrinology (2013) 38(10):1985-93. doi:10.1016/j. psyneuen.2013.03.003

47. Smith AS, Ågmo A, Birnie AK, French JA. Manipulation of the oxytocin system alters social behavior and attraction in pair-bonding primates, Callithrix penicillata. Horm Behav (2010) 57(2):255-62. doi:10.1016/j.yhbeh.2009.12.004

48. Bales KL, van Westerhuyzen JA, Lewis-Reese AD, Grotte ND, Lanter JA, Carter CS. Oxytocin has dose-dependent developmental effects on pair-bonding and alloparental care in female prairie voles. Horm Behav (2007) 52(2):274-9. doi:10.1016/j.yhbeh.2007.05.004

49. Kent K, Arientyl V, Khachatryan MM, Wood RI. Oxytocin induces a conditioned social preference in female mice. JNeuroendocrinol (2013) 25(9):803-10. doi:10.1111/jne.12075

50. Sigling HO, Wolterink-Donselaar IG, Spruijt BM. Home seeking behavior in rat pups: attachment vs. kin selection, oxytocin vs. vasopressin. Eur J Pharmacol (2009) 612(1-3):48-53. doi:10.1016/j.ejphar.2009.03.070

51. Cavanaugh J, Carp SB, Rock CM, French JA. Oxytocin modulates behavioral and physiological responses to a stressor in marmoset monkeys. Psychoneuroendocrinology (2016) 66:22-30. doi:10.1016/j. psyneuen.2015.12.027

52. Cavanaugh J, Huffman MC, Harnisch AM, French JA. Marmosets treated with oxytocin are more socially attractive to their long-term mate. Front Behav Neurosci (2015) 9:251. doi:10.3389/fnbeh.2015.00251

53. Saito A, Izumi A, Nakamura K. Food transfer in common marmosets: parents change their tolerance depending on the age of offspring. Am J Primatol (2008) 70(10):999-1002. doi:10.1002/ajp.20593

54. Burkart JM. Opposite effects of male and female helpers on social tolerance and proactive prosociality in callitrichid family groups. Sci Rep (2015) 5:9622. doi:10.1038/srep09622

55. Burkart JM, Fehr E, Efferson C, vanSchaik CP. Other-regarding preferences in a non-human primate: common marmosets provision food altruistically. Proc Natl Acad Sci U S A (2007) 104(50):19762-6. doi:10.1073/pnas.0710310104

56. Chang SWC, Barter JW, Ebitz RB, Watson KK, Platt ML. Inhaled oxytocin amplifies both vicarious reinforcement and self reinforcement in rhesus macaques (Macaca mulatta). Proc Natl Acad Sci U S A (2012) 109(3):959-64. doi:10.1073/pnas.1114621109

57. Brosnan SF, Talbot CF, Essler JL, Leverett K, Flemming T, Dougall P, et al. Oxytocin reduces food sharing in capuchin monkeys by modulating social distance. Behaviour (2015) 152(7-8):941-61. doi:10.1163/1568539X-00003268

58. Caldwell HK, Lee H-J, Macbeth AH, Young WS. Vasopressin: behavioral roles of an "original" neuropeptide. Progress Neurobiol (2008) 84(1):1-24. doi:10.1016/j.pneurobio.2007.10.007

59. Wersinger SR, Caldwell HK, Christiansen M, Young WS. Disruption of the vasopressin $1 \mathrm{~b}$ receptor gene impairs the attack component of aggressive behavior in mice. Genes Brain Behav (2007) 6(7):653-60. doi:10.1111/j.1601-183X.2006.00294.x

60. Wersinger SR, Ginns EI, O'Carroll A-M, Lolait SJ, Young WS III. Vasopressin $\mathrm{V} 1 \mathrm{~b}$ receptor knockout reduces aggressive behavior in male mice. Mol Psychiatry (2002) 7(9):975-84. doi:10.1038/sj.mp.4001195

61. Luppino D, Moul C, Hawes DJ, Brennan J, Dadds MR. Association between a polymorphism of the vasopressin $1 \mathrm{~B}$ receptor gene and aggression in children. Psychiatr Genet (2014) 24(5):185-90. doi:10.1097/YPG.0000000000000036

62. Zai CC, Muir KE, Nowrouzi B, Shaikh SA, Choi E, Berall L, et al. Possible genetic association between vasopressin receptor $1 \mathrm{~B}$ and child aggression. Psychiatry Res (2012) 200(2-3):784-8. doi:10.1016/j.psychres.2012.07.031

63. Feldman R, Gordon I, Zagoory-Sharon O. Maternal and paternal plasma, salivary, and urinary oxytocin and parent-infant synchrony: considering stress and affiliation components of human bonding. Dev Sci (2011) 14(4):752-61. doi:10.1111/j.1467-7687.2010.01021.x

64. French JA, Taylor JH, Mustoe AC, Cavanaugh J. Neuropeptide diversity and the regulation of social behavior in New World primates. Front Neuroendocrinol (2016) 42:18-39. doi:10.1016/j.yfrne.2016.03.004

65. Song Z, McCann KE, McNeill JK, Larkin TE, Huhman KL, Albers HE. Oxytocin induces social communication by activating arginine-vasopressin 
V1a receptors and not oxytocin receptors. Psychoneuroendocrinology (2014) 50:14-9. doi:10.1016/j.psyneuen.2014.08.005

Conflict of Interest Statement: The authors declare that the research was conducted in the absence of any commercial or financial relationships that could be construed as a potential conflict of interest.
Copyright (c) 2017 Taylor, Intorre and French. This is an open-access article distributed under the terms of the Creative Commons Attribution License (CC BY). The use, distribution or reproduction in other forums is permitted, provided the original author(s) or licensor are credited and that the original publication in this journal is cited, in accordance with accepted academic practice. No use, distribution or reproduction is permitted which does not comply with these terms. 